\title{
Titanium Reagents in Heterocyclic Synthesis
}

\author{
Hari Om ${ }^{1}$, Pratibha Choudhary ${ }^{1}$, Poonam Devi ${ }^{1, *}$, Varun Sharma ${ }^{2}$ \\ ${ }^{1}$ Department of Chemistry, Deenbandhu Chhotu Ram University of Science and Technology, Murthal (Sonipat), 131039, India \\ ${ }^{2}$ Department of Chemistry, Hindu College, University of Delhi, Delhi, 110007, India
}

\begin{abstract}
This review confronts the diversity and selectivity of titanium reagents that mediate heterocyclic synthesis. Applications of different titanium based reagents in various organic reactions leading to the formation of heterocyclic compounds are discussed. Among others, epoxide-opening arene annulations, intramolecular coupling of carbonyl groups intermolecular hydroamination, intra mo lecular aza-Heck, reg ioselective synthesis of indoles, anti-Markovnikov hydration of internal and terminal alkynes, and the synthes is of polyarylpyrroles under micro wave conditions, are revie wed.
\end{abstract}

Keywo rds Hetrocyclic, Hydroamination, Polyarylpyrro les, Reg ioselective, Titanium

\section{Introduction}

Transition metals mediated reactions are one of the most attractive methods in synthetic organic chemistry.[1] These metals catalyzed reactions offer promising range of selectivities such as chemoselectivity, regioselectivity, diastereoselectivity, enantioselectivity and atom economy, among others. A wide range of heterocyclics are now accessible following novel and efficient pathways based on intra-molecular cross-coupling of functional groups. Titanium is widely used among the various transition metals employed for the synthesis of heterocyclic compounds. Pinacol and McMurry coupling reactions are the most powerful methods for constructing carbon-carbon bonds and have served as the key step in the synthesis of various heterocyclics, natural products and pharmacologically active compounds.[2] Synthesis of substituted pyrroles from alkynes, imines, and carbon monoxide via an organotitanium intermediate or from alkynes, nitriles, imines, and titanium-imine complexes have been reported.[3,4] The indole ring system is a crucial structure in drug discovery and has become an essential component in many pharmacologically active compounds. Regioselectively substituted pyrroles represent indispensable structural motifs of biologically active natural products and molecular sensors.[5]

This review explores the recent literature, and describes organic synthes is applications and developments in mechanistic understanding of hetrocyclic synthes is catalyzed by different titanium reagents such as $\mathrm{TiCl}_{4}, \mathrm{Cp}_{2} \mathrm{TiCl}_{2}$, $\mathrm{Cp}_{2} \mathrm{TiMe}_{2}, \mathrm{TiCl}_{4}-\mathrm{BINOL}, \mathrm{TiO}_{2}$, and $\mathrm{Ti}(\mathrm{IV})$-isopropoxide.

* Corresponding author:

pmud.chem@gmail.com (Poonam Devi)

Published online at http://journal.sapub.org/ajoc

Copyright (C) 2012 Scientific \& Academic Publishing. All Rights Reserved

\section{Titanium (IV) Chloride}

Titanium chlorides are the most important and much widely used catalyst for different synthetic applications. McMurry coupling reaction has extended the scope of low-valent titanium chemistry beyond the classical reductive dimerization of aldehydes and ketones to alkenes.[6] Titanium chloride promotes the intramolecular coupling of carbonyl groups of distinctly different redox potentials competently. This has open a new and flexible entry into hetro- aromatic compounds such as furans, benzo(b)furans, pyrroles and indoles by reductive cyclization of oxo-ester or oxo-amides as depicts in the Scheme 1. [7-9]

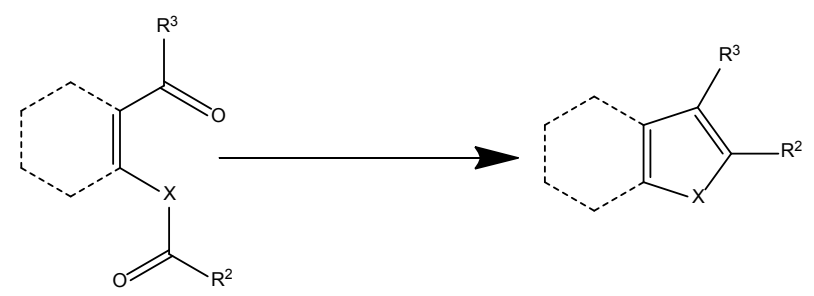

Scheme 1. Reductive cyclization for the synthesis of hetrocyclics, $X=O$, NR

A user friendly procedure for intermolecular hydroamination reactions which employs inexpensive and readily available $\mathrm{TiCl}_{4}$ has been reported.[10] Ackermann and coworker used $\mathrm{TiCl}_{4} / t-\mathrm{BuNH}_{2}$ as catalyst for hydroamination based Fisher Indole synthesis. The reaction commence with the addition of 1,1-disubstituted hydrazines onto aryl and alkyl-substituted alkynes catalyzed by the addition of $t-\mathrm{BuNH}_{2}$ to a solution of $\mathrm{TiCl}_{4}$ in toluene competently.[11] (Scheme 2) In this process, hydrazine is directly converted to the indole derivative. 


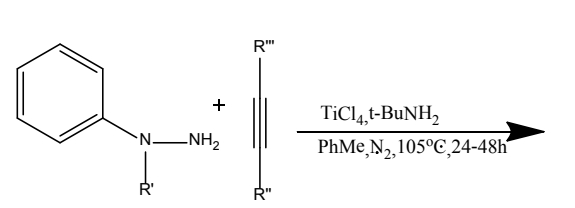

(N)

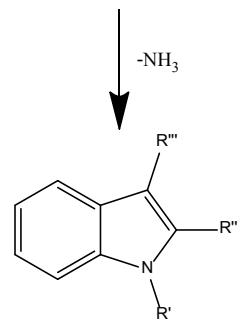

Scheme 2. Regioselective synthesis of indoles catalyzed by $\mathrm{TiCl}_{4} / \mathrm{t}-\mathrm{BuNH}_{2}$

Similarly, Abbiati et al. have reported $\mathrm{TiCl}_{4} / \mathrm{t}-\mathrm{BuNH}_{2}$ med iated hydro-amination/annulations reaction of $\alpha$-keto-ac etylenes.[12] The hydroamination of unsymmetrically substituted alkynes proceed with excellent regioselectivity with a single regioisomer. Ackermann group have also reported another titanium chloride based regioselective synthes is of indoles. This reaction begins with a user friendly $\mathrm{TiCl}_{4}$ catalyzed intermolecular hydroamination of 2-chloro aniline and a subsequent palladiu m cataly zed intramo lecular aza-Heck reaction. 2-chlorophenyl substituted enamine is formed in one-pot procedure (Scheme 3).[13] Unsymmetric al substituted alkynes enable the synthes is of diversely functionalized indoles with regioselectivity.

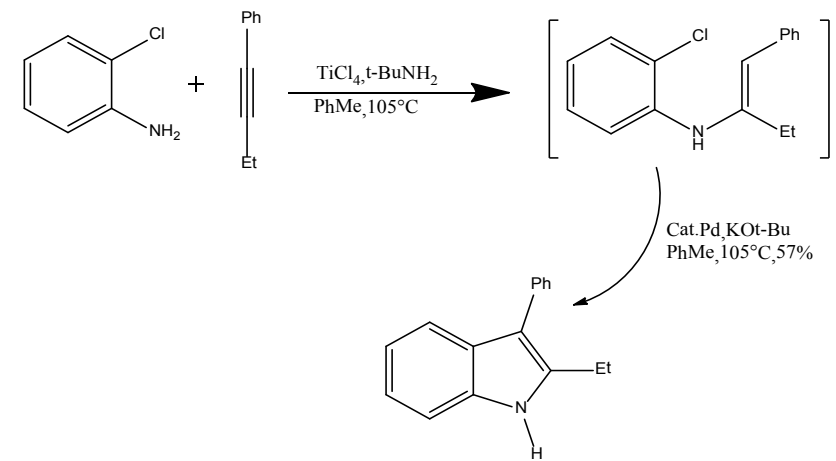

Scheme 3. One-pot synthesis of indole used for opt imization of palladium catalyst

Hydroamination reactions of alkynes catalyzed by Zirconium and Titanium lay down the stage for the development of Titanium based hydroamination catalysts. [14-19] The inexpensive precatalyst $\mathrm{TiCl}_{4}$ was employed for intermolecular hydroamination reactions of alkynes.[20] The regios elective functionalization of unsymmetrical substitute d alkynes has primary importance in synthetic organic chemistry.[21] Ackermann have described a new method for the preparation of substituted benzo(b)furans.[22] The methodology for the indirect anti-Markovnikov hydration of unsymmetrical substituted terminal and internal alkynes is based on $\mathrm{TiCl}_{4}$ cataly zed hydroamination reactions followed by a Copper-catalyzed O-ary lation. Ortho-alkylarene gets converted into substituted benzo(b)furan. (Scheme 4)

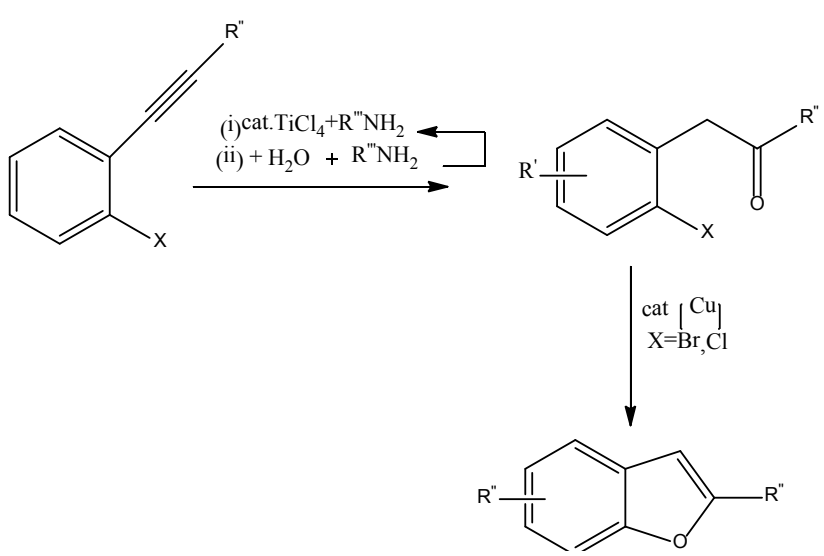

Scheme 4. Synthesis of substituted benzo(b)furan

However, more selective anti-Markovnikov hydration of internal and terminal alkynes was attained using more sterically hindered amines. The synthesis of substituted pyrroles from 1,3-diketones and imines at room temperature using $\mathrm{TiCl}_{4} / \mathrm{Zn}$ or $\mathrm{TiCl}_{4} / \mathrm{Sm}$ in anhydrous THF is reported.[23] Later on highly regioselective synthesis of substituted pyrroles utilizing low-valent titanum reagent was reported.[24]

Rao et al. have accounted facile one-pot synthesis of polyarylpyrroles from 2-butene and but-2-yne-1,4-diones under microwave conditions.[25] Substituted pyrroles are obtained in good yields via the novel coupling cyclization reaction of 1,3-diketones with imines promoted by low-valent titanium reagent. Synthesis of substituted pyrroles from 1,3-diketones and imines has been performed at room temperature using $\mathrm{TiCl}_{4} / \mathrm{Zn}$ or $\mathrm{TiCl}_{4} / \mathrm{Sm}$ in anhydrous THF.[26,27] Similarly, Dou and coworkers have reported the synthes is of highly regios lective polysubstituted pyrroles through three component reaction induced by low-valent titanium.[28] 1,3-diketone, aldehydes and amines are treated with the low-valent titanium reagent prepared from Titanium (IV) chloride and Samarium powder in anhydrous $\mathrm{THF}$ at room temperature under a nitrogen atmosphere. The cyclization product (1,2,3,5-tetrasubstituted pyrrole) is obtained in good yield. (Scheme 5)

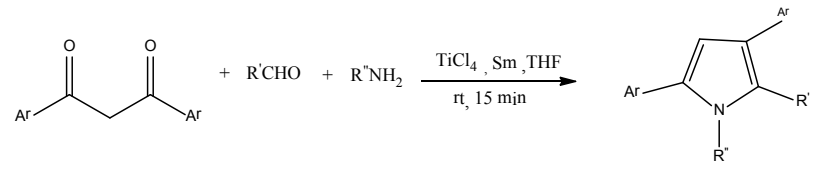

Scheme 5. Synthesis of three component polysubst ituted pyrroles

Under the same condition, this method can be applied to the aromatic aldehydes with either electron-withdrawing groups (such as halide groups) as well as electron-donating groups (such as alkyl and alkoxyl groups) and aliphatic aldehydes. The advantage of this method includes easily accessible starting materials, short reaction time, high yields, regioselectivity, and convenient manipulation, a mong others. In another report, Ackermann et al. have described the synthes is of pyrrole through titanium catalyzed inter-molec ular hydroamination reaction through diasteromeric mixture of chloroenyes.[29] Synthes is of pyrrole utilizes $\alpha$-haloalky 
nols through a reaction sequence comprising dehydration, intermolecularhydroamination, [1,5] H-sig matropic shift and intramolecular nucleophilic substitution. (Scheme 6)

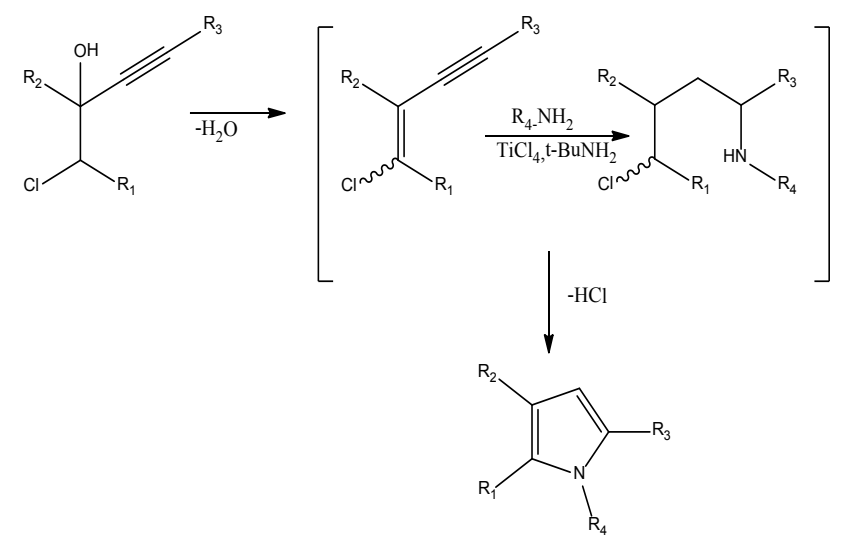

Scheme 6. Titanium catalyzed synthesis of pyrrole using $\alpha$-haloalkynols

Duan et al. achieved a total synthesis of cicerfuran, a naturally occurring benzofuran compound using a simple procedure and readily available reagents.[30] This synthetic approach promotes the scope of cross McMurry reaction and provide a novel approach for the facile synthesis of 2-ary lbenzofurans. In another paper, Abbiati and coworkers have described a $\mathrm{TiCl}_{4} / t$ - $\mathrm{BuNH}_{2}$-mediated synthesis of pyrrolo[1,2- $a]$ indole-2-carbaldehydes, starting from 2-acyl-1-propargyl-1 $H$-indoles under mild reaction conditions.[31] (Scheme 7)
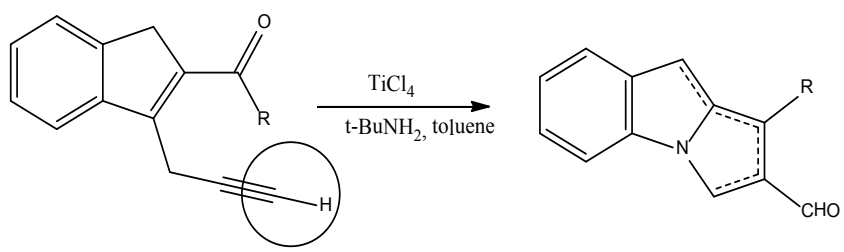

Scheme 7. Synthesis of pyrrolo-[1,2-a]indole-2-carbaldehydes

Application of $\mathrm{TiCl}_{4}$ as catalyst extends to the synthes is of aromatic thiazoles. 2-Arylbenzothiazole has been prepared from bis-(2-benzalaminophenyl)disulfide using titanium tetrachloride and samarium powder in anhydrous tetrahydrofuran (Scheme 8).[32] Disulfides give the expected products either bearing electron-withdrawing groups (such as halide) or electron-donating groups (such as alkyl and alko xy l groups) under the same reaction conditions with moderate to good yields. The electronic nature of the substituent has no significant effects on this reaction.<smiles>CC(C)Sc1ccccc1/N=C/[Al]</smiles>


Scheme 8. Synthesis of 2-Arylbenzothiazole
Titanocene chloride is a well-known reagent for generating carbon-centred radicals from epoxides.Diastereo selective inter- and intramolecular pinacol couplings of aldehydes have been reported using a titanium(III) complex. [33,34] Zhou and Hirao reported catalytic reductive cyclization of olefinic iodoethers by use of $\mathrm{Cp}_{2} \mathrm{TiCl}_{2}$ in the presence of $\mathrm{Mn}$ and $\mathrm{Me}_{3} \mathrm{SiCl}$.[35] (Scheme 9) This protocol provides a versatile method for the selective formation of multisubstituted tetrahydrofurans. In the absence of $\mathrm{Cp}_{2} \mathrm{TiCl}_{2}$, this reaction led to a much lower yield.<smiles>C=CCOC(CI)c1ccc(O[N+](=O)[O-])cc1</smiles>

Scheme 9. Preparation of multi-subst ituted tetrahydrofuran

Diastereoselective inter- and intra-molecular pinacol coupling of aldehydes have been reported using a titanium(III) complex.[36] Jana and Roy have developed a method to synthesize benzopyrans by radical cyclization of aromatic carbonyl compounds using titanium(III) chloride as the radical initiator.[37] The radical initiator $\left(\mathrm{Cp}_{2} \mathrm{TiCl}\right)$ is prepared in situ from commercially available titanocene dichloride $\left(\mathrm{Cp}_{2} \mathrm{TiCl}_{2}\right)$ and zinc dust in THF under argon. (Scheme 10) Intermolecular coupling product is the major product when $\mathrm{Cp}_{2} \mathrm{TiCl}$ was added in the normal way. However, slow addition of carbonyl compound to the reagent $\left(\mathrm{Cp}_{2} \mathrm{TiCl}\right)$ yields the cyclized product in good yield without any of the coupling product.

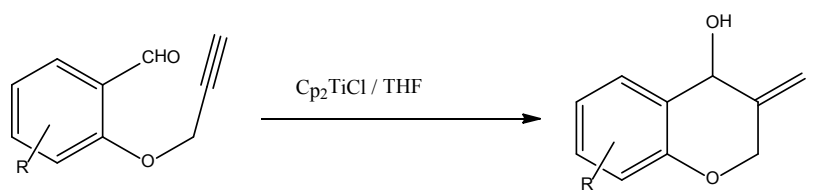

Scheme 10. Radical cyclization of aromatic carbonyl compounds using $\mathrm{Cp}_{2} \mathrm{TiCl}$ promoted<smiles>[Y]c1ccc2c(c1)NCC2(C)CO</smiles>

Scheme 11. Preparation of 3,3-disubstituted 5-azaindoline

Wipf and Maciejewski have developed a novel titanocene (III) chloride catalyzed epoxide-opening arene annulation that affords 3,3-disubstituted indulines. $3 \mathrm{~mol} \%$ of titanocene dichloride and stoichio metric manganese tolerate a range of substituents on the aromatic ring.[38] This methodology can be extended to other five-membered heterocycles as demonstrated by the preparation of a 3,3-disubstituted 5-azaindoline. (Scheme11) 
In another paper, Maciejewski and Wipf reported the conversion of $\mathrm{N}$-epo xya lky lanilines into indolines catalyzed by Titanocene (III) Chloride.[39] The reaction proceeds through Curtius rearrangement of the known carboxylic acid followed by subsequent trapping of the intermediate isocyanate with benzyl alcohol afford ing the Cbz-protected aminopyridine in 33\% yield over 3 steps. (Scheme 12) Subsequent methally lation and epoxidation using $m$-CPBA led to epoxide, which on treatment with catalytic titanocene(III) chloride in the presence of stoichiometric manganese powder, provided an intermed iate 4,6-dichloro5 -azaindoline. Further conversion of this intermed iate with $\mathrm{Pd} / \mathrm{C}$ under an atmosphere of $\mathrm{H}_{2}$ gave azaindoline in $52 \%$ yield over 2 steps.

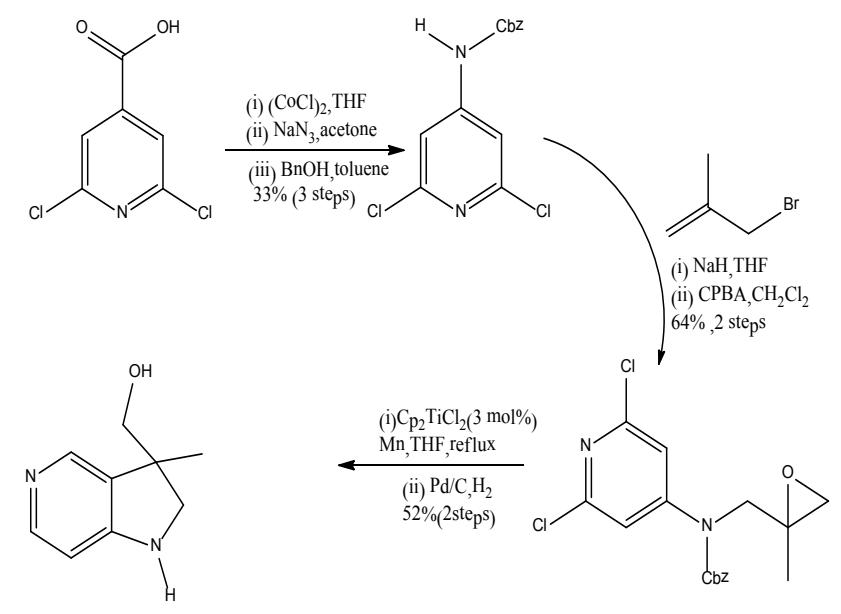

Scheme 12. Preparation of 5-azaindolene

\section{4. $\mathrm{Cp}_{2} \mathrm{TiMe}_{2}$}

Petasis reagent (dimethyltitanocene, $\mathrm{Cp}_{2} \mathrm{TiMe}_{2}$ ) has proven to be very effective for the methylenation of esters. $[40,41] \mathrm{Cp}_{2} \mathrm{TiCl}_{2}$ also serves as a precursor for the synthes is of $\mathrm{Cp}_{2} \mathrm{TiMe}_{2}$. A new synthetic entry to the 1,4-dihydroquinoline nucleus involves dimethyltitanocene catalysed methylenation of $\mathrm{N}$-(alkoxycarbonyl)amides derived from 2-allylanilines, followed by ring-closing metathesis of the resulting enamides.[42,43] Bytschkov and Doye have reported intra-molecular hydroamination/ cyclization of aminoalkynes catalyzed by $\mathrm{Cp}_{2} \mathrm{TiMe}_{2}$.[44] This catalyst has been found a competent catalyst for the intra molecular hydroamination/cyclization of a minoalkynes The hydroamination reactions proceed smoothly in the presence of $5.0 \mathrm{~mol} 1 \% \mathrm{Cp}_{2} \mathrm{TiMe}_{2}$ at $100-110^{\circ} \mathrm{C}$ to give fiveand six-membered cyclic imines within 4-6 hours. After subsequent reduction with zinc-modified $\mathrm{NaBH}_{3} \mathrm{CN}$ at room temperature cyclic amines can be isolated in good yields. In combination with an imine reduction, the intramolecular hydroamination reactions can be used for a convenient one-pot synthesis of cyclic amines from aminoalkynes. (Scheme 13)



Scheme 13. One-pot synthesis of cyclic amines from aminoalkynes by $\mathrm{Cp}_{2} \mathrm{TiMe}_{2}$ catalyzed intramolecular hydroamination and subsequent reduction

Indoles have also been synthesized via alkylidenation of acylphenylhydrazides using phosphoranes and the Petasis reagent, followed by in situ thermal rearrangement of the product enehydrazines. The Petasis reagent provides an essentially neutral equivalent of the [acid-catalysed] Fischer indole synthesis with acyl phenylhydrazides as starting substrates.[45] (Scheme 14) Alkylidene triphenylphosphoranes convert aryl phenylhydrazide to indoles, but acyl phenylhydrazides derived from aliphatic carboxylic acids undergo a Brunner reaction to form indolin-2-ones.

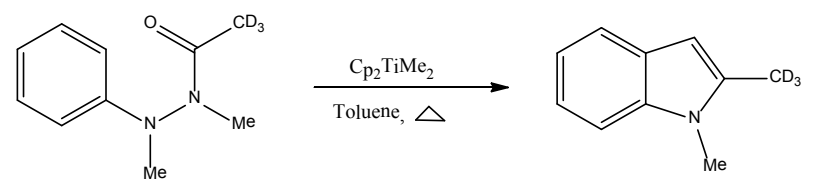

Scheme 14. Synthesis of sust it uted indole from acyl phenylhydrazides

\section{5. $\mathrm{TiCl}_{4}-\mathrm{BINOL}$}

Zhao and coworkers have reported a simple and efficient catalytic enantioselective hetero-Diels-Alder reaction between $(E)$-4-methoxy-2-trimethylsilo xy-penta-1, 3-diene and aromatic aldehydes catalyzed by $\mathrm{TiCl}_{4}-(R)$-BINOL catalytic system using sodium alcoholates as additives. Aromatic aldehydes were used and provided relative product yield (61-88\%) yields and with good to excellent enantioselectivities.[46] Yu et al. reported asymmetric synthesis of 2,6-substituted dihydropyrone catalyzed by 3-monosubstituted and 3,3-bisubstituted BINOL titanium complexes where asymmetric hetero-Diels-Alder (HDA) reactions of aromatic aldehydes with Danishefsky's diene derivative were carried out smoothly in the presence of the Ti(IV)-(R)-BINOL (1:1.2) complex to give the corresponding chiral 2,6-disubstituted dihydropyrones under mild conditions.[47] Aromatic aldehydes afford the corresponding products in moderate yields (up to $72 \%$ ) with good enantioselectivities (up to $80 \%$ ee). Aromatic aldehydes afforded the corresponding products in moderate yields (up to $72 \%$ ) with good enantioselectivities (up to $80 \%$ ee). 
Highly enantioselective hetero-Diels-Alder reaction of trans-1-Methoxy-2-methyl-3-trimethyls ilo xybuta-1,3-diene with aromatic and aliphatic aldehydes catalyzed by 3-substituted BINOL-Titanium complex are reported.[48] 3-Diphenylhydro xy methyl-substituted BINOL-titanium co mplex (prepared in situ) is found to be a highly efficient catalyst for hetero-Diels-Alder reaction of diene with both aromatic and aliphatic aldehydes to give 2,5-disubstituted dihydropyrone in up to $99 \%$ yield and $99 \%$ ee. (Scheme 15 )

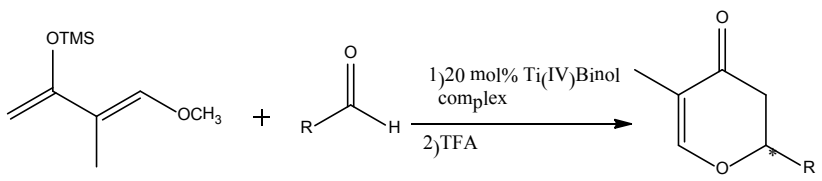

Scheme 15. Synthesis of 2,5-disubst it ut ed dihydropyrone

$R$-BINOL-Ti( $\mathrm{O} i \mathrm{Pr})_{4}$ complex displayed high enantiosel ectivity in the asymmetric HDA reaction of diene with both aromatic and aliphatic aldehydes. Majumder and coworkers reported titanium-catalyzed 3-component coupling of primary amine, alkyne, and is onitrile followed by treatment with hydrazines provides pyrazoles in a one-pot procedure. This new procedure has significant flexibility. [49]

\section{Miscellaneous Reagents}

Park et al. reported a one-pot synthes is of 4-ethoxy-1,2,3, 4-tetrahydroquinoline from a heterogeneous solution of nitroarene, ethanol and $\mathrm{TiO}_{2}$ upon irradiation by UV light.[50] (Scheme 16)
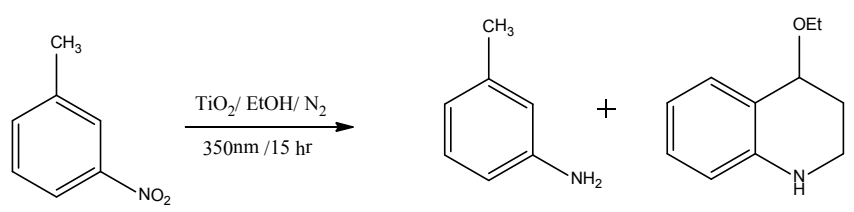

Minor

environmentally acceptable modification of Biginellis reaction. (Scheme 17)

Havaldar et al. synthesize various 2-substituted benzimid azoles in one pot by condensation of o-phenylenediamine with an appropriate aldehyde using a mixture of Titanium (IV) isopropoxide and cumene hydroperoxide.[52] (Scheme 18)



Scheme 18. Synthesis of 2-substituted benzimidazoles using a mixture of $\mathrm{Ti}(\mathrm{IV})$ isopropoxide and cumene hydroperoxide

\section{Conclusions}

Transition metal mediated reactions are one of the most attractive methods in synthetic organic chemistry. Analys is of a variety of titanium reagents in hetrocyclic synthes is has revealed that their efficiency strongly depends on the nature of the active titanium species and the experimental conditions. The reasons that explain the interest shown by many researchers includes, among others, regio- and stereochemical control of the reaction, together with the mildness of the experimental conditions which include the use of catalytic quantities of titanium.

The rapid access to indoles as well as the selection of environmentally benign and chemoselective methods are the major goals in heterocyclic synthes is using titanium reagents based catalysts. The exploration for new annulations and heterocyclization procedures is a very competitive and determined research field. Many organic reactions catalyzed by titanium reagents are presented involving the use of transition-metal complexes (especially palladiu m co mp lexes, but many other transition- and main-group metals and their complexes are continuously being studied and introduced in the chemistry of heterocycles, thermal reactions, photochemical procedures, solid-support synthes is for a combinatorial approach, green procedures with the auxiliary techniques of mic rowaves and ultrasound for environmental friendly reaction conditions.

\section{REFERENCES}

Scheme 17. Synthesis of dihydropyrimidin-2(1H)-ones/thiones by $\mathrm{T} \mathrm{iO}_{2}$

Kassaee et al. reported three-component, one-pot condensation for the synthes is of dihydropyrimidin $-2(1 \mathrm{H})-\mathrm{o}$ nes/thiones ones through a three-component condensation of 1,3-dicarbonyl compounds, aldehydes, and urea, using commercially available titania $\left(\mathrm{TiO}_{2}\right)$ as heterogeneous and recyclable catalyst under neutral and solvent-free conditions.[51] This method provides efficient, facile, and

[1] Soderberg, B. C. G. Coord. Chem. Rev. (2003), 241, 147.

[2] (a) Fürstner, A., Bogdanovic, B. Angew. Chem. Int. Ed. Engl.(1996),35, 2442. (b) Gansauer, A.; Bluhm, H. Chem. Rev. (2000), 100, 2771. (c) Armbruster, J.; Grabowski, S.; Ruch, T.; Prinzbach, H. Angew. Chem. Int. Ed. Engl. (1998), 37, 2242. (d) McMurry, J. E. Chem. Rev. (1989), 89, 1513. (e) Kahn, B. E ; Rieke, R. D. Chem. Rev. (1988), 88, 733. (f) Ephritikhine, M.; Villiers, C. in Modern Carbonyl Olefination,Takeda, T. Ed., Wiley-VCH, Weinheim, (2004), 223. (g) Fürstner, A., in Transition Metals for Organic 
Synthesis $\left(2^{\text {nd }}\right.$ Ed.), Beller, M.; Bolm, C. Eds., Wiley-VCH, Weinheim, (2004), 1, 449. (h) Dushin, R. G. in Comprehensive Organometallic Chemistry II, Hegedus, L. S. Ed., ergamon, Oxford,(1996 ), 12, 1071. (i) Robertson, G. M. In Comprehensive Organic Synthesis I, Trost, B.M. Ed. Pergamon, New York, (1991), 3, 563.

[3] Gao, Y.; Yoshida, Y.; Sato, F. Tetrahedron Lett. (1996), 37 $7787-7790$

[4] Gao, Y.; Yoshida, Y.; Sato, F. Synlett (1997), 1353-1354.

[5] For selected reviews, see: (a) Bellina, F.; Rossi, R. Tetrahedron (2006), 62, 7213-7256. (b) Balme, G. Angew. Chem., Int. Ed. (2004), 43, 6238-6241. (c) Fuerstner, A Angew. Chem., Int. Ed. (2003), 42, 3582-3603. (d) Hoffmann, H.; Lindel, T. Synthesis (2003), 1753-1783. (e) Novak, P.; Mueller, K.; Santhanam, K. S. V.; Haas, O. Chem. Rev. (1997), 97, 207-281.

[6] (a) McMurry, J. E.; Chem. Rev. (1989), 1513-1524. (b) Lect, ka, T. in Active metals Preparations., Characterization, Applications (Furstner, Ed.) VCH, Weinheim. (1995), 85-131.

[7] (a) Furstner, A; Jumbam, D. N.; Tetrahedron (1992), 48, 5991-6010. (b) Furstner, A.; Jumbam, D. N.; Wiedmann, H.; Tetrahedron Lett. (1991), 6695-6696. (c) Furstner, A.; Jumbam, D. N; J. Chem. Soc. Chem. Commun. (1993), 211-212. (d) Furstner, A; Jumbam, D. N.; Seidel, J.; Chem. Ber. (1994), 1125-1130. (e) Furstner, A.; Weintritt, H.; Hupperts, A.; J. Org. Chem. (1995), 60, 6637-6641.

[8] (a) Furstner, A.; Hupperts, A.; Ptock, A.; Jansen, E.; J. Org. Chem. (1994), 59, 5215-5229. (b) Furstner, A.; Ptock, A.; Weintritt, H.; Goddard, R.; Kruger, C.; Angew. Chem. Int. (1995), 34, 725-728. (c) Furstner, A.; Ernst, A.; Tetrahedon (1995), 51, 773-786.

[9] Furstner, A; Hupperts, A.; J. Am. Chem. Soc. (1995), 117, 4468-4475.

[10] Ackermann, L.; Organometallics (2003), 22, 4367-4368.

[11] Ackermann, L.; Born, R.; Tetrahedron Letter (2004), 45, 9541-9544.

[12] Abbiati, G.; Casoni, A.; Canevari, V.; Nava, D.; Rossi, E.; Org. Lett. (2006), 8, 4839-4842.

[13] Ackermann, L.; Sandmann, R; Villar, A; Kaspar, T. L.; Tetrahedron (2008), 64, 769-777.

[14] Pohlki, F.; Doye, S.; Chem. Soc. Rev. (2003), 32, 104-114.

[15] For a first titanium-catalyzed intermolecular hydroamination of an alkyne, see: (a) Hill, J. E.; Profilet, R. D.; Fanwick, P. E.; Rothwell, I. P. Angew. Chem. Int. Ed. Engl. (1990), 29, 664-665. (b) McGrane, P. L.; Jensen, M.; Livinghouse, T.; J. Am. Chem. Soc. (1992), 114, 5459-5460. (c) McGrane, P. L.; Livinghouse, T.; J. Org. Chem.(1992), 57, 1323- 1324. (d) Polse, J. L.; Andersen, R. A.; Bergman, R. G.; J. Am. Chem. Soc. (1998), 120, 13405-13414.

[16] Pohlki, F.; Doye, S.; Chem. Soc. Rev. (2003), 32, 104-114.

[17] (a) Walsh, P. J.; Hollander, F. J.; Bergman, R. G.; J. Am. Chem. Soc. (1988), 110, 8729-8731. (b) Walsh, P. J.; Baranger, A. M.; Bergman, R. G.; J. Am. Chem. Soc. (1992), 114, 1708-1719. (c) Duncan, A. P.; Bergman, R. G.; Chem. Rec. (2002), 2, 431-445.
[18] (a) Buil, M. L.; Esteruelas, M. A.; Lopez,A. M.; Mateo, A. C.; Onate, E.; Organometallics (2007), 26, 554-565. (b) Swartz, D. L.; Odom, A. L.; Organometallics (2006), 25, 6125-6133. (c) Smolensky, E.; Kapon, M.; Eisen, M. S.; Organometallics (2005), 24, 5495-5498. (d) Tillack, A.; Khedkar, V.; Jiao, H.; Beller, M.; Eur. J. Org. Chem. (2005), 5001-5012. (e) Hoover, J. M.; Petersen, J. R.; Pikul, J. H.; Johnson, A. R.; Organometallics (2004), 23, 4614-4620. (f) Heutling, A.; Pohlki, F.; Doye, S.; Chem. Eur. J. (2004), 10, 3059-3071. (g) Zhang, Z.; Schafer, L. L.; Org. Lett. (2003), 5, 4733-4736. (h) Lorber, C.; Choukroun, R.; Vendier, L. Organometallics (2004), 23, 1845-1850. (i) Shi, Y.; Ciszewski, J. T.; Odom, A. L.; Organometallics (2001), 20, 3968-3969.

[19] (a) Odom, A. L.; Dalton Trans. (2005), 225-233. (b) Bytschkov, I.; Doye, S.; Eur. J. Org. Chem. (2003), 935-946.

[20] (a) Ackermann, L.; Organometallics (2003), 22, 4367-4368. (c)Ackermann, L.; Kaspar, L. T.; Gschrei, C.; J. Chem. Commun. (2004), 2824- 2825.

[21] (a) Beller, M.; Seayad, J.; Tillack, A.; Jiao, H. Angew. Chem., Int. Ed.), (2004), 43, 3368-3398. (b) Alonso, F.; Beletskaya, I. P.; Yus, M. Chem. Rev. (2004), 104, 3079-3159.

[22] Ackermann, L. Kaspar,T. L. J. Org. Chem. (2007), 72, 6149-6153.

[23] Shi, D. Q.; Shi, C. L.; Wang, X. S.; Zhuang, Q. Y.; Tu, S. J.; Hu, H. W.; Synlett (2004), 2239-2241.

[24] Shi, D. Q; Shi, C. L.; Dou, G.; Zingy, Li.; Synthesis (2007), 20, 3117- 3124 .

[25] Rao, H. S. P.; Jothilingam, S.; Scheeren, H. W. Tetrahedron ( 2004), 60, 1625-1630

[26] Shi, D. Q.; Shi, C. L.; Wang, X. S.; Zhuang, Q. Y.; Tu, S. J.; Hu, H. W. Synlett. (2004), 2239-2241.

[27] Shi, D. Q.; Dou, G. L.; Shi, C. L.; Li, Z. Y.; Ji, S. J. Synthesis (2007), 20, 3117-3124.

[28] Dou, G.; Shi, C.; Shi, D.; J. Combinatorial Chem. (2008), 10, 811-813.

[29] Ackermann, L.; Sandmann, R.; Kaspar, L. T; Org. Lettt (2009), 11, 2031.

[30] Duan, F. X.; Bin Zhang, B. Z. Z. J; Fu, G. Ziy, Beijing J. Org. Chem. (2007), 72, 10283-10286.

[31] Abbiati, G.; Casoni, A.; Canevari, V.; Nava, D.; Rossi, E. Org. Lett. (2006), 21, 4839-4842

[32] Shi, D. Q.; Feng, S.; Rong, Dou, G. L.; Synth. Commun, (2010), 40, 2302-2310.

[33] Rajanbabu, T. V.; Nugent, W. A. J. Am. Chem. Soc. (1994), 116,986

[34] (a) Gansauer, A.; Bauer, D. J. Org. Chem. (1998), 63, 2070. (b) Yamamoto, Y.; Hattori, R.; Miwa, T.; Nakagai, Y.; Kubota, T.; Yamamoto, C.; Okamoto, Y.; Itoh, K. J. Org. Chem. (2001), 66, 3865.

[35] Zhou, L.; Hirao, T.; J. Org. Chem. (2003), 68, 1633-1635.

[36] (a) Gansauer, A.; Bauer, D. J. Org. Chem. (1998), 63, 2070. 
[37] Jana, S.; Roy, S. C.; Tetrahedron Lett. (2006), 47, 5949-5951.

[38] Wipf, P.; Maciejewski, P. J.; Org. Lett. (2008), 10, 4383-4386.

[39] Maciejewski, J. P.; Wipf, P. ARKIVOC (2011), 6, 92-111.

[40] Okazoe, T.; Takai, K.; Oshima, K.; Utimoto, K. J. Org. Chem. (1987), 52, 4410-4412.

[41] Petasis, N. A.; Bzowej, E. I. J. Am. Chem. Soc. (1990), 112, 6392-6394.

[42] Bennasar, M. L.; Roca, M.; Manuel Monerris, M.; Diaz, D. G. Tetrahedron Lett. (2005), 46, 4035-4038.

[43] Macleod, C.; Austin,C. A.; Hamprecht, D. W.; Hartley, R. C. Tetrahedron Lett. (2004), 45, 8879-8882.

[44] Bytschkov, I.; Doye, S.; Tetrahedron Lett. (2002), 43, 3715-3718.
[45] Hisler, K.; Aurélien; Commeureuc, G. J. C.; Zhou, S.; Murphy, J. A.; Tetrahedron Lett. (2009), 50, 3290-3293.

[46] Zhao,Y.C.; Zhang, J.; Wang, N.; Yu, H.; Yang, X. B.; Chen, S. Y.; Yu, X. Q.; Lett. in Org. Chemi. (2008), 5, 391-395.

[47] Yu, H.; Zhang, J.; Zhao, Y. C.; Wang, N.; Wang, Q.; Yang, X. B.; Yu, X. Q.; Chem. Papers, (2008), 62, 187-193.

[48] Yang, X. B.; Feng, J.; Zhang, J.; Wang,; Wang, L.; Liu, J. L.; Yu, X. Q, Org. Lett. (2008), 10, 1299-1302.

[49] Majumder, S.; Gipson, K. R.; Staples, R. J.; Odom.; A. L. Adv. Synth. Catal. (2009), 351, 2013 - 2023.

[50] Park, K. H.; Joo, H. S.; Ahn, K.; Jun, K.; Terahedron Lett. (1995), 36, 5943-5946.

[51] Kassaee, M. Z.; Masrouri, H.; Movahedi, F.; Mohammadi, R. Helvetica Chimica Acta (2010), 93, 261-264.

[52] Havaldar, H. F.; Mule, G.; Dabholkar, B.; Synth. Commun. (2011), 41, 2304-2308. 